\title{
AUTO-ARQUIVAMENTO E ACESSO ABERTO: DEVERES E DIREITOS DIGITAIS NA SOCIEDADE DE REDE
}

\author{
Rodrigo Duarte Ferrari ${ }^{1}$ \\ Giovani De Lorenzi Pires ${ }^{2}$
}

\begin{abstract}
Resumo: Este artigo é o produto de uma investigação sobre o auto-arquivamento em repositórios digitais como uma relação de direitos e deveres no contexto da sociedade em rede e do acesso aberto. Partimos de um estudo de caso sobre a percepção de pesquisadores brasileiros sobre os usos e propósitos do Repositório Institucional da Rede CEDES (RIRC). Isto criou condições para observar e refletir sobre o compromisso social e político dos pesquisadores da Rede CEDES em organizar e disponibilizar as produções dessa ação ministerial em acesso aberto. Realizamos dez entrevistas com os pesquisadores da Rede CEDES no período de 19/11/2010 até 14/09/2011 e utilizamos algumas estatísticas do RIRC e da própria rede como dados. Nesse texto, apresentamos uma discussão sobre o autoarquivamento no RIRC a partir de três conceitos principais: distribuição coletiva; inteligência coletiva, cultura participativa. Como resultado desta pesquisa, observamos que há contradições entre um discurso pautado pelas qualidades ideais dos repositórios digitais e do acesso aberto em contraste com a prática efetiva que deveria materializar esse discurso.
\end{abstract}

Palavras-chave: Auto-arquivamento. Acesso aberto. Repositórios digitais.

Abstract: This article presents an investigation into the self-archiving in digital repositories as a relationship of rights and duties in the context of the network society and open access. We start with a case study on the perception of Brazilian researchers about the uses and purposes of the Institutional Repository of CEDES Network. This created conditions to observe and reflect on the social and political commitment of the researchers of CEDES Network to organize and make available their products of that ministerial action in open access. We conducted ten interviews with researchers of CEDES Network in the period of 19/11/2010 to 14/09/2011 and used some statistics of the RIRC and the network itself as data. In this text, we present a discussion about self-archiving in RIRC from three main concepts: collective distribution; collective intelligence; participative culture. As a result of this research, we found that there are contradictions between discourse guided by the ideal qualities of digital repositories and open access in contrast to the effective practice that should materialize this discourse.

Keywords: Self-archiving. Open access. Digital repositories.

\footnotetext{
${ }^{1}$ Licenciado e Mestre em Educação Física pela UFSC. Pesquisador do LaboMídia/UFSC. Pesquisador no Núcleo de Infância Comunicação e Arte (NICA). Brasil. E-mail: rd.ferrari@gmail.com

${ }^{2}$ Licenciado em Educação Física (UFSM,1978). Professor associado do Departamento de Educação Física da UFSC, Docente, Orientador credenciado no PPGEF/UFSC. Co-editor da revista Motrivivência e coordenador do LaboMídia - /UFSC. Brasil.E-mail: giovani.pires@ufsc.br Recebido em: 18/02/2013 - Aceito em: 06/11/2013.
} 


\title{
INTRODUÇÃO
}

Castells (2010) denomina a organização social, econômica e política que emerge por volta da década de 1980 de Sociedade em Rede. De acordo com essa definição, a globalização da economia, a informação, o conhecimento, o uso e desenvolvimento de Tecnologias de Informação e Comunicação (TICs) ocupam o centro dessa recente configuração.

\begin{abstract}
A mudança contemporânea de paradigma pode ser vista com uma transferência de uma tecnologia baseada principalmente em insumos baratos de energia para uma outra que se baseia predominantemente em insumos baratos de informação derivados do avanço da tecnologia em microeletrônica e telecomunicações (FREEMAN citado por CASTELLS, 2010, p. 107).
\end{abstract}

Nesse contexto, o acesso à informação e ao conhecimento científico se destacam ainda mais nos projetos de construções de sociedades democráticas no século XXI. Em acordo com esta perspectiva, a comunidade acadêmica mundial mobilizou esforços e criou um movimento político conhecido como Open Access, traduzido nesse artigo como acesso aberto (HUNGRIA, 2002). Nesse primeiro encontro oficial do acesso aberto, foi redigido e assinado um documento em torno de dois princípios fundamentais: 1) As informações e os conhecimentos científicos, sobretudo, os financiados com recursos públicos devem ser disponibilizados para toda humanidade de forma irrestrita; e 2) A internet se configura como o meio tecnológico capaz de viabilizar o princípio anterior.

Seguindo os preceitos do acesso aberto, Harnad (2004a) propõe que isso deva ser realizado por meio de periódicos científicos e pelo depósito das publicações dos pesquisadores em sistemas de informação chamados repositórios digitais. Segundo o autor, ambos devem ter políticas de uso claras e alinhadas com os princípios do acesso aberto. A primeira alternativa, a dos periódicos, é denominada de via dourada, a segunda, dos repositórios digitais, de via verde. Nesta pesquisa concentramos a atenção no caminho verde do acesso aberto.

Em 2000 a Universidade de Southampton criou o Eprints, que segundo Harnad (2010a) possibilitou que toda universidade utilizasse o sistema para disponibilizar em acesso aberto as produções de suas respectivas instituições. Foi assim que surgiu o termo repositório institucional e na sequência vários deles foram desenvolvidos, entretanto, o autor recorda que a maioria permaneceu quase vazio, 
pois estima-se que $85 \%$ dos pesquisadores não auto-arquivavam suas produções mesmo após a criação de repositórios digitais. Por meio deste e de outros exemplos, o autor compreende que garantir o auto-arquivamento é o maior desafio do acesso aberto e a solução que pode gerar os maiores impactos em direção à universalização do acesso à informação e ao conhecimento científico.

$\mathrm{O}$ auto-arquivamento ${ }^{3}$ é definido como o depósito efetuado pelos próprios pesquisadores de suas respectivas produções científicas em repositórios digitais de acesso aberto. Esse comportamento é caracterizado pelo compartilhamento de informações e conhecimentos científicos no formato digital, que surgem no ciberespaço ${ }^{4}$.

Segundo Lévy (2010), o ciberespaço já se configura como um dos principais locais de preservação da memória humana, interação e comunicação no início do século XXI. Esse processo continua crescendo, sobretudo, com a operacionalização da convergência digital no âmbito das TICs, em que a quantidade, qualidade e acessibilidade de variados aparelhos ampliam o consumo, a produção e veiculação de conteúdos digitais em larga escala.

Torna-se possível, então, que comunidades dispersas possam comunicar-se por meio do compartilhamento de uma telememória na qual cada membro lê e escreve, qualquer que seja sua posição geográfica. Uma outra função importante do ciberespaço é a transferência de dados ou upload. Transferir um arquivo consiste em copiar um pacote de informações de uma memória digital para outra, geralmente de uma memória distante para a de meu computador pessoal ou aquela do local onde trabalho fisicamente (LEVY, 2010, p. 96).

Entretanto, precisamos observar com cautela os desdobramentos concretos dessa convergência técnica no âmbito cultural. Segundo Jenkins (2009), o ciberespaço vem transformando a maneira como a indústria midiática produz e veicula conteúdos nos meios de comunicação, porque a fronteira técnica que separava emissores de receptores foi extinta. Isso significa que qualquer pessoa com acesso à internet pode produzir e veicular informações para todo mundo e isso gera novas necessidades de

\footnotetext{
${ }^{3}$ Disponível em: http://www.eprints.org/openaccess/self-faq/. Acesso em 01/11/2011.

${ }^{4}$ Eu defino o ciberespaço como um espaço de comunicação aberto pela interconexão mundial dos computadores e das memórias dos computadores. Essa definição inclui o conjunto dos sistemas de comunicação eletrônicos (ai incluídos os conjuntos de redes hertzianas e telefônicas clássicas), na medida em que transmitem informações provenientes de fontes digitais ou destinadas a digitalização (LÉVY, 2010, p. 95).
} 
formação, especialmente nas emergentes possibilidades de exercício da cidadania no ciberespaço. $\mathrm{O}$ autor denomina essas relações de cultura participativa e uma de suas potencialidades é a capacidade de resolução de problemas de forma colaborativa.

Jenkins (2011) categoriza algumas habilidades e competências necessárias para a formação de cidadãos capazes de atuar criticamente no contexto da cultura participativa, das quais destacamos duas ${ }^{5}$ : a) cognição distribuída; b) inteligência coletiva. Segundo o autor a cognição distribuída é definida pela transição de uma noção de cognição centrada apenas no indivíduo, para um modelo cognitivo que considera outras pessoas, o ambiente e situações. Isso se materializa no ciberespaço e os repositórios digitais de acesso aberto são exemplos de ferramentas que possibilitam a distribuição cognitiva.

A distribuição cognitiva cria condições para o surgimento da inteligência coletiva, caracterizada pela coordenação de ações em redes de trabalho e utilização de informações e conhecimentos distribuídos no ciberespaço para buscar soluções coletivas para problemas comuns à uma determinada comunidade (LÉVY, 2010). Porém, a inteligência coletiva é uma noção recente frente aos modelos tradicionais de educação e formação humana, fato que gera a necessidade de conceber e experimentar novas transformações de nossas relações com a informação e com o conhecimento.

Uma das novidades provenientes dessas considerações que apresentamos é a intensificação dos deveres e responsabilidades dos pesquisadores em disponibilizar na rede mundial de computadores suas produções em formato digital e com acesso aberto. Dessa forma, delimitamos nosso foco em torno das reflexões relativas ao compromisso social e político dos pesquisadores em agir de acordo com a proposta de acesso aberto num âmbito normativo. Para isso nos fundamentamos, sobretudo, em Habermas (1989).

Discutimos questões práticas do tipo: “O que devo/devemos fazer?", na pressuposição de que a resposta não possa ser qualquer uma; nós nos acreditamos capazes em princípio de distinguir as normas e mandamentos corretos dos falsos. Se, por um lado, as proposições normativas não são passíveis de verdade em sentido estrito, por conseguinte não no mesmo sentido em que os enunciados descritivos podem ser verdadeiros ou falsos, temos que colocar o problema de explicar o sentido de "verdade moral" (...) (HABERMAS, 1989, p. 77).

${ }^{5}$ Estas duas competências foram definidas originalmente por Lévy (2010). 
Segundo Habermas (1989), esse tipo de problema moral divide os filósofos do século XX e XXI em duas perspectivas antagônicas, os que defendem e os que negam a possibilidade de fundamentar a validade universal de normas e mandados ${ }^{6}$. O autor os denomina respectivamente de cognitivistas e céticos. Habermas (1989) se associa aos cognitivistas e amplia a defesa dessa perspectiva com base nos trabalhos do psicólogo Lawrence Kohlberg e no conceito de chegar a um entendimento desenvolvido em sua própria teoria do agir comunicativo. Com isto, o autor apresenta uma possibilidade de compreensão da moral que se fundamenta tanto na filosofia, quanto na ciência. $\mathrm{O}$ conceito central desta abordagem é a busca pelo entendimento mútuo a partir dos fundamentos da teoria do agir comunicativo (1989).

Os processos de entendimento mútuo visam um acordo que depende do assentimento racionalmente motivado ao conteúdo de um proferimento. $\mathrm{O}$ acordo não pode ser imposto à outra parte, não pode ser extorquido ao adversário por meio de manipulações: o que manifestamente advém graças a uma intervenção externa não pode ser tido na conta de um acordo. Este assenta-se sempre em convicções comuns (HABERMAS, 1989, p. 165).

Diante da organização desse contexto teórico reunimos alguns elementos para fundamentar o acesso aberto como uma relação de direitos e deveres concernidos. No campo empírico, observamos e refletimos sobre os usos do Repositório Institucional da Rede CEDES (RIRC) ${ }^{7}$. Os Centros de Desenvolvimento do Esporte Recreativo e do Lazer (Rede CEDES) é uma ação do Ministério do Esporte (ME) que financia pesquisas científicas em esporte e lazer com recursos públicos desde 2003 (FERRARI, 2012).

Nesse cenário, compreendemos que o RIRC é uma iniciativa inovadora, tanto do ponto de vista técnico quanto da perspectiva política da gestão da informação e do conhecimento no Brasil, sobretudo em esporte e lazer. Avaliamos que esse contexto forma um fértil campo de investigação e, por isso, tomamos o RIRC como o objeto de estudo (FERRARI, 2012), apresentada em 2012 como dissertação de mestrado ao

\footnotetext{
${ }^{6}$ Nesse trabalho estamos traduzindo a expressão mandate por mandado. De acordo com Harnad (2010b), os mandados são entendidos como um conjunto de normas que determinam os deveres e os direitos de uma determinada comunidade de usuários de um repositório digital. No Brasil, alguns autores preferem traduzir mandate como mandato. Compreendemos que os significados das duas palavras são bastante semelhantes, porém, segundo o dicionário on-line priberam (http://www.priberam.pt/dlpo/default.aspx?pal=mandado) interpretamos que a palavra mandado é a única que denota de forma mais clara a ideia de um conjunto de normas.

${ }^{7}$ Disponível em: http://www.labomidia.ufsc.br/redecedes/. Acesso em 3 de Junho de 2012.
} 
Programa de Pós-Graduação em Educação Física da Universidade Federal de Santa Catarina (PPGEF/UFSC), tendo como um dos focos investigar:

como a proposta de desenvolvimento do RIRC é percebida pelos pesquisadores da Rede CEDES, em relação ao compromisso social e político de tornar disponíveis, de forma organizada e permanente, as informações e conhecimentos produzidos pela rede?

Como consequência deste questionamento, descrevemos, analisamos e refletimos neste texto a percepção dos pesquisadores da Rede CEDES relativa ao RIRC, considerando as características, propósitos e funcionalidades da ferramenta para gerir informações e conhecimentos.

Do ponto de vista metodológico esta pesquisa se caracterizou como um estudo de caso (BOGDAN; BINKLEN, 1991) que tomou o RIRC como seu objeto de análise $^{8}$. A técnica de pesquisa que utilizamos foi a observação participante, escolha que nos permitiu estudar o RIRC e a comunidade da Rede CEDES a partir e "por dentro" dela.

O instrumento principal de produção dos dados foram 10 (dez) entrevistas semi-estruturadas, realizadas com os coordenadores de núcleos e projetos de pesquisas da Rede CEDES. As entrevistas aconteceram entre novembro/2010 e setembro/2011. Os pesquisadores foram selecionados de acordo com a relevância e histórico de participação na rede ${ }^{9}$, assim como a localização geográfica, para abranger quatro regiões do país ${ }^{10}$. Seis entrevistas foram realizadas presencialmente, três via videoconferência e uma por troca de correspondência eletrônica (email). Em média cada entrevista durou uma hora, todas foram gravadas em formato audiovisual, transcritas e enviadas para os pesquisadores aprovarem o conteúdo.

Diante deste quadro metodológico, o desenho investigativo dessa pesquisa se caracteriza predominantemente como um estudo qualitativo (GOELLNER et al, 2010). Também trabalhamos com descrições analíticas e dados quantitativos da Rede CEDES e do RIRC. Esses dados foram coletados a partir da data de lançamento

\footnotetext{
${ }^{8}$ Projeto de pesquisa aprovado pelo comitê de ética da UFSC, processo no 1907.

${ }^{9}$ Selecionamos preferencialmente pesquisadores que fazem parte da Rede CEDES desde a criação dessa ação ministerial e tem participação permanente e destacada nela.

${ }^{10}$ Sul (Rio Grande do Sul, Santa Catarina e Paraná); Sudeste (São Paulo, Minas Gerais); Nordeste (Bahia), Centro-Oeste (Goiás, Brasília). A ausência do Norte se justifica pela participação muito recente de universidades da região na Rede CEDES e com pequeno número de instituições conveniadas.
} 
oficial do RIRC, 19 de junho de 2010, até 14 de setembro de 2011, pois essa foi a data da última entrevista realizada e marcou o fim da fase de coleta de dados. Os dados quantitativos e qualitativos foram triangulados e apresentados a partir de eixos de discussões.

Na pré-análise do material de campo, um dos eixos temáticos foi denominado O RIRC no contexto da cultura participativa. Neste eixo foi incluído um sub-eixo, Desdobramentos do RIRC, porque este sub-eixo foi desenvolvido com uma unidade apenas relativamente autônoma. Estes eixos temáticos foram criados com base nos critérios que Bardin (2009) denomina de exclusão mútua, ou seja, a partir da definição de uma identidade clara e homogênea.

De acordo com essas considerações introdutórias, apresentaremos a seguir uma síntese das discussões sobre o auto-arquivamento e o acesso aberto como direitos e deveres dos pesquisadores e cidadãos que pertencem à sociedade em rede.

\section{O RIRC NO CONTEXTO DA CULTURA PARTICIPATIVA}

Todos os entrevistados reconhecem o RIRC como uma importante ação da Rede CEDES, mas na prática esse discurso se torna contraditório, pois menos de $20 \%$ do potencial do RIRC está sendo aproveitado pelos pesquisadores da Rede CEDES. Em certa medida esses dados não representam uma novidade ou anomalia no âmbito do desenvolvimento de outros repositórios digitais. De acordo com Harnad (2010b), os repositórios digitais que não funcionam de acordo com um mandado que normatize esse comportamento rigorosamente, possuem em média, uma porcentagem de autoarquivamento de $15 \%$. Com base nesses dados, identificamos alguns tópicos que nos permitem refletir sobre essa realidade, por exemplo, a percepção entre os entrevistados de que o RIRC representa uma inovação no campo do esporte e lazer brasileiro.

É preciso compreender que estamos aprendendo muito e em pouco tempo, é importante termos paciência com a comunidade acadêmica para poder incorporar gradativamente cada uma dessas etapas do processo de produção do conhecimento (Dra. Ana Márcia Silva, entrevista realizada 14/07/2011).

O repositório é algo que inova o campo no que se refere às formas de difusão e de troca, por isso acho que o campo ainda não acolheu o repositório tão bem assim (Dr. Fernando Mascarenhas, entrevista realizada $25 / 05 / 2011$ ). 
O RIRC é uma ferramenta que surge a partir das recentes possibilidades de transformações culturais vinculadas à expansão do ciberespaço, especialmente, a partir do conceito de inteligência coletiva (LÉVY, 2010), no sentido do surgimento de novas possibilidades de práticas colaborativas e trabalho em rede. Jenkins (2009) denomina esse contexto de potenciais mudanças de cultura participativa, sendo que os repositórios digitais e o auto-arquivamento são exemplos que funcionam de acordo com essa lógica. Por isso, concordamos com os entrevistados que o RIRC representa uma novidade que sofre ainda certo estranhamento junto à comunidade da área.

Entretanto, compreendemos que as principais inovações do RIRC são conceituais, pois o uso técnico da ferramenta obedece à mesma lógica de sistemas já consolidados no campo acadêmico do esporte e lazer. Estamos nos referindo aos periódicos no SEER e aos trabalhos submetidos a congressos via SOAC, que possuem o processo comum de cadastro do usuário, preenchimento dos metadados e submissão dos arquivos digitais. Os principais periódicos da área utilizam a plataforma SEER e o principal congresso, CONBRACE, utiliza o SOAC desde 2008. Por outro lado, observamos que a proposta conceitual de auto-arquivamento não mobilizou significativamente os pesquisadores da Rede CEDES a utilizarem o RIRC, ao contrário do que vêm ocorrendo com a utilização do SEER e SOAC.

O retorno para o pesquisador no que se refere à avaliação, principalmente dos periódicos, onde existe interesse (avaliação) dos pesquisadores em publicar nesses espaços, enquanto no repositório ganha menos o pesquisador e mais o campo (Fernando Mascarenhas, entrevista realizada 25/05/2011).

No campo acadêmico brasileiro publicar os resultados de pesquisas, sobretudo, em periódicos é uma questão de sobrevivência, especialmente dos profissionais que atuam em programas de pós-graduação. Portanto, se cadastrar em periódicos eletrônicos e utilizar essas ferramentas para submeter trabalhos envolve um alto grau de interesse pessoal por parte dos pesquisadores, pois a permanência e o prestígio desses profissionais na pós-graduação dependem desse comportamento. No caso dos repositórios digitais, esse interesse é mais fraco.

(...) somente os professores que estão vinculados aos programas de pósgraduação já se colocaram em pauta a questão da divulgação do conhecimento e precisam fazer isso pela própria sobrevivência do sistema 
de pós graduação, mas fazemos isso mais enfaticamente naquilo que nos dá um resultado imediato, no Lattes (Ana Márcia, entrevista realizada 14/07/2011).

Segundo Leite (2009), os benefícios para os pesquisadores que auto-arquivam suas produções em repositórios são: organização da informação e do conhecimento da rede de trabalho que eles participam; aumento da visibilidade e impacto de suas pesquisas; prestação de contas com a sociedade; ampliação das possibilidades de diálogo entre os pesquisadores da própria rede e com a sociedade em geral.

Com base nos princípios do acesso aberto (HUNGRIA, 2002), compreendemos que o auto-arquivamento se justifica como um dever moral (seguindo Habermas), sendo que os interesses pessoais dos pesquisadores são secundários nesse processo. O RIRC é um projeto de interesse público e defendemos que o auto-arquivamento é um compromisso social e político dos pesquisadores que são financiados com recursos públicos. Se os pesquisadores concordarem que suas profissões pertencem a um projeto coletivo orientado pela construção democrática do nosso país, eles não precisam de mais nenhum motivo, além deste, para auto-arquivar suas produções no RIRC.

Entretanto, essa tensão entre interesses públicos e privados extrapola as fronteiras do RIRC e se configura como um desafio que permeia a estrutura da Rede CEDES como um todo. De acordo com os pesquisadores da Rede CEDES, a própria organização do trabalho em rede ainda é um processo que está em construção, pois "não há muita tradição na produção em rede ainda" (Dr. Giuliano Pimentel, entrevista realizada 30/06/2011) no campo do esporte e lazer brasileiro. Para Castells (2010) a organização em rede é o novo paradigma da organização econômica que começa a se estruturar na década de 1980 com a transição dos modelos industriais fordistas para o toyotismo. Essa estrutura prevê o aumento da eficiência no campo do trabalho por meio do investimento em ações colaborativas, flexibilidade e descentralização de cargos e funções, maior autonomia nos processos de tomada de decisões e do investimento para facilitar o fluxo das informações, comunicações e conhecimentos. Porém, ao mesmo tempo que essa proposta aumenta a eficiência da organização e resultados do trabalho, ela é mais difícil de ser estruturada. 
O repositório da rede funcionaria melhor se a rede de fato funcionasse como uma rede, no que se refere ao trabalho colaborativo. Quando os pesquisadores da Rede CEDES eram chamados a se reunir, o debate sempre passava pela construção da rede, os desafios que encontrávamos enquanto rede. Nunca nos pautamos nessa dificuldade em desenvolver um trabalho colaborativo no cotidiano, talvez fosse interessante que a rede já tivesse um espaço ao longo de sua construção de difusão presencial de seus trabalhos. Congressos ou encontros da rede em que pudéssemos conhecer os trabalhos uns dos outros, para criar unidade, e ao conhecer $o$ que os outros grupos estão produzindo buscar acessar (Dr. Fernando Mascarenhas, entrevista realizada 25/05/2011).

Concordamos que a aproximação dos pesquisadores da Rede CEDES é um fator decisivo para construir a unidade dessa iniciativa, tanto fora como dentro do ciberespaço. Entre as dificuldades inerentes a esse processo, destacamos que muitos pesquisadores da Rede CEDES relataram que exercem diversas outras funções. Geralmente, esses profissionais são docentes de cursos de graduação e pós-graduação, ocupam cargos administrativos em suas respectivas instituições, coordenam outras pesquisas e prestam serviços de consultoria para iniciativas públicas e privadas, ou seja, estão sujeitos a uma alta carga de trabalho e responsabilidades que se somam as da Rede CEDES. Respeitamos a complexidade desse contexto, mas em hipótese alguma consideramos que essa realidade justifique a sub-utilização do RIRC e o prejuízo da Rede CEDES (e de toda a comunidade da área), pois não podemos relativizar o entendimento de que os pesquisadores devem “(...) ter a obrigatoriedade de veicular suas pesquisas, pois o dinheiro que eles estão recebendo é público” (Dra. Gisele Schwartz, entrevista realizada 20/06/2011). Também destacamos que participar da Rede CEDES não é uma obrigação, ou seja, cada pesquisador deve avaliar se é capaz, ou não, de se integrar à rede e cumprir com suas responsabilidades.

Argumentamos que nas condições colocadas pela Dra. Gisele Schwatrz e com os fundamentos da consciência moral e do agir comunicativo (HABERMAS, 1989), o auto-arquivamento como relação de deveres e direitos é legitima, tanto do ponto de vista moral quanto na possibilidade de criação de leis no âmbito do direito positivo. Com isso, as normas moralmente aceitas e válidas pela comunidade da Rede CEDES devem ser sistematizadas na forma de um contrato objetivo e claro que defina as obrigações de cada integrante da rede, assim como as consequências caso esse acordo nãos seja cumprido. Isso representa a necessidade de elaboração de um mandado que 
garanta o auto-arquivamento no RIRC de acordo com o inciso $37^{\circ}$ do $5^{\circ}$ artigo da Constituição da República Federativa do Brasil de 1988.

Nos editais da Rede CEDES de 2009 e 2011, respectivamente, as referencias às obrigações dos pesquisadores com o RIRC são as seguintes:

13.5. Os convênios firmados deverão apresentar como produtos: a) relatório impresso da pesquisa, digitalizado e indexado no Repositório da Rede CEDES, pelo coordenador de pesquisa, após parecer da avaliação da prestação de contas (MINISTÉRIO DO ESPORTE, 2009, sem grifo no original).

14.5. Os convênios firmados deverão apresentar como produto final:

a) relatório impresso da pesquisa, digitalizado e indexado no Repositório da Rede CEDES, pelo coordenador de pesquisa, após parecer da avaliação da prestação de contas (MINISTÉRIO DO ESPORTE, 2011, sem grifo no original).

De acordo com o item 13.5. do edital de 2009 entendemos que o autoarquivamento dos relatórios de cada pesquisa financiada pela Rede CEDES configurava-se como um mandado, isto é, era um dever de cada coordenador de pesquisa. Nesse caso, a principal falha desse documento é não objetivar o que acontece ao responsável pelas pesquisas se o auto-arquivamento não fosse realizado. Por exemplo, coordenadores de pesquisa contemplados com financiamento pelo edital de 2009 e que não procederam ao auto-arquivamento de suas produções puderam submeter novamente propostas ao edital de 2011 (e serem outra vez contemplados), já que este não pressuponha o atendimento ao previsto no edital de 2009 como critério de submissão nem de avaliação de novas propostas. Isso enfraquece a Rede CEDES e principalmente o RIRC, que dificilmente será respeitado como um dever legítimo dos coordenadores de pesquisas financiadas pelo ME, se ele é apenas citado de forma marginal no edital de chamada pública dessa ação ministerial, sem maiores consequências.

Diante desse quadro, concluímos que ainda não existe uma proposta de mandado capaz de garantir o auto-arquivamento e o funcionamento adequado do RIRC pelo caminho do direito positivo. Isso nos impõe o desafio, por enquanto, de pensar a construção do RIRC apenas no âmbito da consciência moral dos pesquisadores e se eles não desejarem utilizar a ferramenta, nada pode ser feito. Inclusive, a ausência de um mandado abre brechas para questionamentos que descaracterizam o próprio RIRC como repositório digital, uma ferramenta 
constitutivamente colaborativa que foi desenvolvida para funcionar por meio do autoarquivamento (HARNAD, 2004).

Por exemplo, um dos pesquisadores entrevistados sustenta que "todos os pesquisadores que recebam recursos públicos devem ter os seus textos e produções colocadas no repositório, não pelo pesquisador, mas sim pelo próprio ME” (Dr. Augusto Cesar Leiro, entrevista realizada 26/05/2011). Respeitamos esse posicionamento, mas de acordo com as características da organização do trabalho em rede, a lógica do auto-arquivamento pelo pesquisador é mais eficiente e moralmente defensável. Ao invés de concentrar no ME a responsabilidade da gestão da informação e do conhecimento da Rede CEDES, com o RIRC basta que cada pesquisador assuma uma pequena parcela dessa responsabilidade. A Dra. Dulce Suassuna acrescenta que:

Se nós não temos como fazer isso, como vocês (ME e LaboMídia administradores do RIRC) vão fazer isso para tantos pesquisadores $e$ universidades? São 44 universidades, ou seja, é muita coisa. Pelo menos nós da UnB temos diversas publicações que ainda não conseguimos depositar no RIRC. Mas, o que foi possível nós encaminhamos (Dra. Dulce Suassuna, entrevista realizada 07/07/2011).

As palavras da Dra. Dulce Suassuna exemplificam os fundamentos da proposta de auto-arquivamento do RIRC, uma ferramenta que foi concebida de acordo com as recentes transformações das TICs que Tim O'Reilly ${ }^{11}$ chama de Web 2.0. Nesse cenário, a autonomia, o compartilhamento e a colaboração são características centrais nos processos de comunicação e socialização das informações e conhecimentos. Dessa forma, ressaltamos novamente que estamos nos referindo ao RIRC como uma experiência concreta de distribuição cognitiva e inteligência coletiva (LÉVY, 2010) que ocorrem em torno das relações que se estabelecem na formação de uma cultura participativa (JENKINS, 2009). Portanto, compreendemos que centralizar a responsabilidade da gestão da informação e do conhecimento seria um retrocesso frente a atual proposta de auto-arquivamento do RIRC e um passo na contra mão das tendências e facilidades de interações e trabalhos que surgem no âmbito da Web 2.0.

Segundo uma das pesquisadoras entrevistadas, a Web 2.0 e outras transformações tecnológicas são percebidas da seguinte forma: "o processo de

\footnotetext{
${ }^{11}$ Disponível em: http://oreilly.com/web2/archive/what-is-web-20.html. Acesso em 06/11/2011.
} 
informatização que vivemos na sociedade da informação é mais complicado para minha geração de pesquisadores mais velhos, do que para os que são mais jovens" (Dra. Dulce Suassuna, entrevista realizada 07/07/2011). A influência da idade nas relações entre as TICs e as pessoas é uma temática complexa, especialmente quando envolve propostas de mudanças culturais. Contudo, o uso de computadores e da internet nas relações de trabalho deixou de ser uma opção e se tornou uma necessidade, isso se aplica às pesquisas da Rede CEDES. No nosso entendimento, a idade dos pesquisadores não é uma variável que impeça ou dificulte a apropriação técnica e conceitual do RIRC, haja vista que o uso técnico do RIRC é menos complexo do que o cadastro e manutenção do currículo Lattes, sistema de informação obrigatório no âmbito da pesquisa e da pós-graduação brasileira.

$\mathrm{O}$ artigo de Prenky $(2001)^{12}$ indica que há diferenças entre os usos e significados das TICs entre jovens alunos que nasceram a partir da década de 1990, nativos digitais, e professores mais antigos, imigrantes digitais. Concordamos com o autor, mas esse argumento deve ser relativizado de acordo com os diferentes contextos culturais. Também compreendemos que após dez anos dessa reflexão proposta por Prensky (2001) alguns imigrantes digitais já tiveram oportunidades e tempo suficiente para se adaptar aos hábitos dos nativos da geração digital. Os pesquisadores da Rede CEDES são exemplos que se enquadram nessa leitura da realidade. Dessa forma, não entendemos que a referencia à idade de alguns dos pesquisadores da Rede seja um argumento que justifique o baixo uso do RIRC, porém, devemos considerar a hipótese de que nossa interpretação da realidade esteja equivocada ou demasiadamente rígida.

A solução pragmática para essa questão, e também para o excesso de trabalho e responsabilidades que integram a rotina dos pesquisadores da Rede CEDES, partiu de uma das pesquisadoras entrevistadas nessa pesquisa. A Dra. Gisele Schwartz propõe que uma prática que poderia minimizar os efeitos dessas dificuldades, seria delegar para os bolsistas mais jovens dos projetos da Rede CEDES a responsabilidade do auto-arquivamento no RIRC.

${ }^{12}$ Disponível em: http://www.marcprensky.com/writing/prensky\%20\%20digital\%20natives,\%20digital\%20immigrants\%20-\%20part1.pdf. Acesso em 3 de Junho de 2012. 
Se em cada projeto nós conseguíssemos um monitor responsável tanto pela sistematização dos dados da própria pesquisa quanto para a divulgação no repositório e para preenchimento dos relatórios adequadamente, acho que acabaria com o problema da gestão da informação (Dra. Gisele Schwartz, entrevista realizada 20/06/2011).

\section{CONCLUSÕES}

Observamos que o RIRC é percebido pelos pesquisadores da Rede CEDES entrevistados como uma iniciativa estratégica no caminho para a qualificação da política pública brasileira em esporte e lazer. Entendemos que apesar de algumas limitações, os entrevistados compreendem os propósitos básicos do sistema, tanto os conceituais quanto os práticos. Porém, esse contexto apresenta profundas contradições entre a reprodução de discursos que enaltecem o RIRC e sua relevância acadêmica, política e social, enquanto que os dados do próprio sistema, do total das produções da Rede CEDES (SCHWARTZ, 2010) e os poucos esforços coletivos dos pesquisadores da rede em relação ao RIRC indicam que ele é sub-utilizado pelos pesquisadores, que usam menos de $20 \%$ da capacidade da ferramenta.

Esse cenário se torna ainda mais problemático ao recordarmos que o projeto de desenvolvimento do RIRC foi demandado e aprovado por representantes de toda comunidade da Rede CEDES, que assumiram publicamente a responsabilidade coletiva referente à construção do RIRC. Ou seja, compreendemos que há uma contradição entre uma representação ideal do RIRC presente no discurso dos integrantes da Rede CEDES que não se materializou a contento na prática. Essas primeiras considerações que apresentamos fornecem sólidos subsídios para interpretarmos que a compreensão do RIRC não é suficiente para mobilizar e garantir satisfatoriamente o uso, assim como as pretensões acadêmicas, sociais e políticas da ferramenta.

Identificar e refletir sobre esses dados não é tarefa simples e nos exige um cuidado redobrado para não reduzir essa realidade de forma maniqueísta. Essa complexidade passa pelas dificuldades descritas por Habermas (1989) e de início envolve um debate filosófico denso no âmbito da moral, especificamente, o posicionamento dicotômico entre os céticos e cognitivistas.

Para refletir sobre esse achado da pesquisa, mesmo que de forma exploratória, direcionamos nossas forças para buscar estratégias capazes de criar condições para 
construir um entendimento coletivo mais profundo sobre o RIRC e o acesso aberto, um entendimento que legitime uma normatização objetiva, sobretudo, para garantir a universalidade $(\mathrm{U})^{13}$ do acesso aberto e do auto-arquivamento com base em Habermas (1989).

Segundo Harnad (2010b), a elaboração e cumprimento de um mandado é um aspecto necessário para objetivar essa normatização. Junto com o mandado, observamos que o entendimento da organização do trabalho em rede e da centralidade da informação e do conhecimento em nossa sociedade (CASTELLS, 2010); do papel da ciberespaço (LÉVY, 2010); e as possibilidades da construção de uma cultura participativa (JENKINS, 2009) são conceitos que poderiam contribuir com o fortalecimento do RIRC e do acesso aberto. Entretanto, isso depende da reestruturação do complexo jogo de interesses que envolvem as decisões do poder público.

\footnotetext{
${ }^{13} \mathrm{O}$ conceito de universal (U) utilizado nesse trabalho foi apresentado no subcapítulo 2.1 desse trabalho. "(U) Toda norma válida tem que preencher a condição de que as conseqüências e efeitos colaterais que previsivelmente resultem de sua observância universal, para a satisfação dos interesses de todo indivíduo possam ser aceitas sem coação por todos os concernidos" (HABERMAS, 1989, p. 147).
} 


\section{REFERÊNCIAS}

ARAGÃO, Lucia Maria de Carvalho. Razão comunicativa e teoria social crítica em Jürgen Habermas. Rio de Janeiro: Tempo Brasileiro, 1992.

BARDIN, Laurence. Análise de Conteúdo, edição revisada e actualizada. Lisboa: Edições 70, 2009.

BOGDAN, Robert; BINKLEN, Sari. Investigação qualitativa em educação: uma introdução à teoria e métodos. Porto/Pt: Porto Editora, 1991.

Busapest Open Access Initiative. 2002. Disponível em:

http://www.soros.org/openaccess/read. Acesso em 12/12/2011

CASTELLS, Manuel. A sociedade em rede. 6. ed. São Paulo: Paz e Terra, 2010.

FERRARI, Rodrigo Duarte. Gestão da informação e conhecimento em esporte e lazer: o caso do repositório institucional da rede CEDES (RIRC). Dissertação (Mestrado em Educação Física). Florianópolis: PPGEF/Universidade Federal de Santa Catarina, 2012. $171 \mathrm{p}$.

goellner, silvana et al. Pesquisa qualitativa na Educação Física Brasileira: marco teórico e modos de usar. Journal of Physical Education/UEM, North America, 21 jul. 2010. doi: 10.4025/reveducfis.v21i3.8682.

HABERMAS, Jürgen. Consciência moral e agir comunicativo. Rio de Janeiro: Tempo Brasileiro, 1989.

HARNAD, Steven et al. The green and the gold roads to Open Access. Nature Web Focus, 2004a.

HARNAD, Steven. The Open Challenge: A Brief History. Public Service Review: European Science \& Technology, 9 . p. 13-15. 2010a. Disponível em: http://eprints.ecs.soton.ac.uk/21816/1/pubservrefFIN.pdf

HARNAD, Steven. Open Access to Research: Changing Researcher Behavior Through University and Funder Mandates. In: EDEM, 2010b: Proceedings of the 4th Inernational Conference on E-Democracy, pp. 13-22, Austrian Computer Society, 2010b.

JENKINS, Henry. Cultura da convergência. 2. ed. São Paulo: Aleph, 2009.

JENKINS, Henry. Confronting the Challenges of Participatory Culture: Media Education for the 21st Century. The MacArthur Fundation, 2011. Disponível em: http://digitallearning.macfound.org/atf/cf/\%7B7E45C7E0-A3E0-4B89-AC9CE807E1B0AE4E\%7D/JENKINS_WHITE_PAPER.PDF. Acesso em 12/12/2011.

LEMOS, Ronaldo. Creative Commons, mídias e as transformações recentes do direito da propriedade intelectual. Revista de Direito da GV, v. 1, n. 1 - p. 181187, maio, 2005. 
LEITE, Fernando César Lima. Como gerenciar e ampliar a visibilidade da informação científica brasileira: repositórios institucionais de acesso aberto. Brasília: IBICT/MCT, 2009.

LÉVY, Pierre. Cibercultura. 3. ed. São Paulo: Editora 34, 2010.

MINISTÉRIO DO ESPORTE. Edital Rede CEDES. 2009. Arquivo pessoal, disponível em pdf.

MINISTÉRIO DO ESPORTE. Edital Rede CEDES. 2011. Disponível em: http://esporte.gov.br/arquivos/snelis/esporteLazer/cedes/editalPelcRedeCedes2011.pd f.

O’RILLEY, Tim. Free Downloads vs. Sales: A Publishing Case Study. 2007. Disponível em: http://radar.oreilly.com/archives/2007/06/free-downloads.html. Acesso em 12/12/2011.

PRENKI, Marc. Digital Natives, Digital Immigrants. From On the Horizon (MCB University Press, Vol. 9 No. 5, October 2001.

TAYLOR, Arlene G.; JOUDREY, Daniel N. The organization of information. 3 ed. Westport: Libraries Unlimited, 2009.

\section{Como citar este artigo:}

FERRARI, Rodrigo Duarte; PIRES, Giovani De Lorenzi. Auto-arquivamento e acesso aberto: deveres e direitos digitais na sociedade em rede. Rev. digit. bibliotecon. cienc. inf., Campinas, SP, v.12, n.1, p.22--38, jan/abr. 2014. ISSN 1678-765X. Disponível em: <http://www.sbu.unicamp.br/seer/ojs/index.php/rbci>. Acesso em: 30 jan. 2014. 